ORIGINAL RESEARCH ARTICLE

\title{
Knowledge, Perception and Level of Male Partner Involvement in Choice of Delivery Site among Couples at Coast Level Five Hospital, Mombasa County, Kenya
}

\author{
James M. Onchong' ${ }^{1 *}$, Tom Were ${ }^{2}$ and Justus O.S. Osero ${ }^{3}$
}

Coast Level Five Hospital, P.O. Box 90231-80100, Mombasa, Kenya ${ }^{1}$, Department of Medical Laboratory Sciences, Masinde Muliro University of Science and Technology P. O. Box 190-50100², Department of Community Health, Kenyatta University, P.O. Box 43844-0100, Nairobi, Kenya ${ }^{3}$.

*For correspondence: Email: jamesonchonga74@yahoo.com; Phone +254 0716957681.

\begin{abstract}
Involvement of males in reproductive health is an important step in reducing maternal and newborn deaths. A number of pregnant women attending Coast Level Five Hospital report waiting for their male partner to discuss and choose the delivery site. Although some do this when already in labour, there are no records on how many practice this and the influence of the couple knowledge and perception on male partner involvement in choice of delivery site. This descriptive cross-sectional study aimed at establishing the level of male partner involvement and influence of couple knowledge and perception on male involvement in choice of delivery site among women who delivered at this facility. Systematic sampling was used to select the participants. A semi-structured questionnaire and focus group discussion guide were used to collect data. Chi-square and binary logistic regression were used for statistical analysis. $40.6 \%$ of male partners were involved in choice of delivery site, women knowled ge $(\chi 2-19.256 ; \mathrm{df}-1 ; \quad \mathrm{p}<0.001)$, women $(\chi 2-11.347 ; \mathrm{df}-1 ; \mathrm{p}=0.001)$ and male partners' perception $(\chi 2-10.909 ; \mathrm{df}-1 ; \mathrm{p}=0.001)$ influenced male partner involvement. However, women knowledge was the only predictor of male involvement (OR-3.843; 95\% CI, 2.082-7.092; $\mathrm{P}<0.001)$. Male partner involvement was low, empowering women and encouraging positive perception among women and male partners will enhance male partner involvement in choice of delivery site. The health workers in Mombasa should come up with health education and communication strategies to improve public knowledge and perception towards male involvement and ultimately improve the level of male partner involvement in choice of delivery site. (Afr J Reprod Health 2016; 20[1]: 71-79).
\end{abstract}

Keywords: Coast Level Five Hospital, Male involvement, Choice of delivery site, Mombasa Kenya, Male partner, Knowledge and perception.

\section{Résumé}

La participation des hommes à la santé de la reproduction est une étape importante dans la réduction de la mortalité maternelle et néonatale. Un certain nombre des femmes enceintes fréquentant l'Hôpital Coast Level Five signalent avoir attendu leur partenaire masculin pour discuter et pour choisir le lieu d'accouchement. Bien que certaines ne le fassent que quand elles sont déjà en travail, il n'y a pas de dossiers sur le nombre des femmes qui la pratique, et linfluence de la connaissance du couple et la perception sur la participation des partenaires de sexe masculin dans le choix du de lieu d'accouchement. Cette étude transversale descriptive s'est donnée comme objectif d'établir le niveau de la participation des partenaires de sexe masculin et l'influence de la connaissance chez les couples et la perception sur la participation des hommes au choix du lieu d'accouchement au sein des femmes qui ont accouché dans cet établissement. L'échantillonnage systématique a été utilisé pour sélectionner les participants. Nous nous sommes servi d'un questionnaire semi-structuré et un guide de groupe de discussion cible pour recueillir des données. Le Chi-carré et la régression logistique binaire ont été utilisés pour l'analyse statistique. $40,6 \%$ des partenaires masculins ont participé au choix du lieu d'accouchement, la connaissance chez les femmes $(\chi 2-19.256$; df-1; $p<0,001)$, les femmes $(\chi 2-11.347$; df-1; $\mathrm{p}=0,001)$ et la perception des partenaires masculins $(\chi 2-10,909 ; \mathrm{df}-1 ; \mathrm{p}=0,001)$ influencé la participation du partenaire masculin. Cependant, les femmes connaissances était le seul facteur prédictif de la participation des hommes (OR-3,843; IC à $95 \%, 2,082$ à 7,$092 ; \mathrm{P}<0,001)$. La participation des partenaires hommes était faible, l'autonomisation des femmes et l'encouragement d'une perception positive chez les femmes et chez les partenaires masculins permettra d'améliorer la participation des partenaires des hommes au choix du lieu d'accouchement. Le personnel de santé à Mombasa devrait élaborer des stratégies d'éducation et de communication sur la santé pour améliorer la connaissance et la perception de la part du public envers la participation des hommes et, d'améliorer, en fin de compte, le niveau de la participation des partenaires de sexe masculin au choix du lieu d'accouchement(Afr J Reprod Health 2016; 20[1]: 71-79).

Mots-clés: Hôpital Coast Level Five, participation des hommes, choix de lieu d'accouchement, Mombasa Kenya, partenaire masculin, connaissance et perception. 


\section{Introduction}

Globally, many women die every day from pregnancy- or childbirth-related complications. For instance, in 2010, 287,000 women died during and following pregnancy and childbirth with $99 \%$ of these deaths occurring in developing countries ${ }^{1}$ such as Kenya with maternal mortality ratio of $488 / 100,000^{2}$, with Involvement of males in reproductive health is an important step in reducing maternal and newborn deaths and for achieving Millennium Development Goals (MDGs) 4 and $5^{3}$. Men's involvement promotes safety of their female partners' pregnancy and childbirth by ensuring access to care and provision of emotional and financial support ${ }^{4}$ and more birth preparedness ${ }^{5}$. In addition, men have social and tremendous control over their partners. They decide the timing and conditions of sexual relations, family size and whether their spouse will utilize available health care services ${ }^{4}$. Therefore this makes male involvement critical in improving maternal health and reducing maternal mortality and morbidity.

Many countries have not developed largescale programs that reach out to men. In Cambodia for instance male involvement in reproductive health is underdeveloped ${ }^{6}$ while in Africa, the role of men in maternity care is under-studied ${ }^{7}$. However, studies show different proportions of male involvement in choice of delivery site. For instance, in Ethiopia one study established high involvement $(90.4 \%)^{8}$. In Senegal, a study showed that $52 \%$ of the decisions on delivery site were made by the husbands ${ }^{9}$. In Uganda, a study in south western Uganda indicates that $56 \%$ of male partners were involved in deciding spouses' place of delivery ${ }^{10}$. In Kenya, the Kenyan Demographic and Health Survey (KDHS) 2008/2009 reported that $73 \%$ of women either made their own decision, or a joint decision with regard to health care $^{2}$. However, in Nyandarua Kenya, $58.4 \%$ of the women interviewed had their place of delivery decided by their husbands ${ }^{11}$. While a study at Asembo Kenya revealed that majority of the women $(87 \%)$ made decisions on delivery site on their own ${ }^{12}$. Despite the positive contributions of male involvement in tackling maternal mortality and morbidity, little is known on their level of involvement in this study area.

Studies have shown that lack of knowledge about maternal health pose a significant challenge to positive male partner involvement ${ }^{13-14}$. Other studies have reported negative perceptions towards men attending ANC services ${ }^{15}$. In countries such as Nepal, demeaning phrases to tease and ridicule men who are involved in RH activities have been coined $^{13,14 \& 16}$. For example, phrases such "swasniko mutma bageko", or a man being "swept away by the urine of the wife" are used to describe a man who takes orders from a wife ${ }^{13 .}$

In Cameroun, fear of being perceived as a jealous husband following his wife around was one of the reasons for lack of involvement in ANC services ${ }^{17}$. In a study in Malawi, it was found that women considered childbirth as a preserve for women only ${ }^{18}$. Men in Western Kenya rarely accompany their partners to the RH clinics, a fact attributed to low awareness, and lack of male reproductive health education programs ${ }^{16}$ while in Busia Kenya, majority of men regarded delivery as a natural phenomenon and hence saw no need of being involved ${ }^{14}$. This study reports the level of male partner involvement in choice of delivery site, the influence of couple knowledge and perception on male partner involvement in choice of delivery site among couples at Coast Level Five Hospital.

\section{Materials and Methods}

\section{Study design, settings and population}

This descriptive cross-sectional study was conducted at the post-natal ward (PNW) at Coast Level Five Hospital, Mombasa County, Kenya. Coast Level Five Hospital is a 672 bed capacity hospital situated at Tononoka area in Mombasa County along Mombasa -Kilifi highway. It was founded in 1908 as a native civil hospital. It serves about 800,000 within its primary catchment area and more than 3 million from the secondary catchment area. It is the main teaching and referral hospital in Coast region. The study participants comprised eligible women who delivered at Coast Level Five Hospital, Mombasa County and their male partners during the duration of the study from January to February 2015. 


\section{Study variables}

The study variables comprised level of male partner involvement, couple Knowledge and perceptions and their influence on male partner involvement in choice of delivery site. The respondents' knowledge was assessed based on their knowledge of the concept of male partner involvement in choice of delivery, awareness of the need for male involvement, whether it is necessary and its benefits. Perception of the respondents was measured based on how they perceived male partners accompanying the spouses to ANC, discussing maternal health issues (FP, ANC etc.), participating in choice of delivery site, and escorting the spouse to the chosen delivery site.

\section{Sample size, sampling and data collection tools}

The sample size consisted of 207 couples. Only couples where the women delivered at Coast Level Five Hospital were included in the study. Systematic sampling was used to select the respondents. A semi-structured interviewer administered questionnaire was used to collect quantitative data. The questionnaire comprised items on socio-demographic characteristics, the role played by the male partner in choice and access of delivery site and couple knowledge of male partner involvement and their perception towards male involvement in selected reproductive health activities. A focus group discussion guide was used to collect qualitative data. A pre-test was carried out at Port Reitz District Hospital involving 10 couples.

\section{Data collection}

Data was collected in January and February 2015. Four third year nursing students from Kenya Medical Training College (KMTC) Mombasa campus were recruited to assist in data collection. The third year nursing students were chosen because they had covered research methodology in their course and were therefore easy to train. In addition, they were in rotation in maternity. The training covered overall research design, communication skills, interviewing and recording information, how to obtain informed consent and ethics in research.

Semi-structured interviews were conducted at the postnatal ward after explaining the study in detail and obtaining consent. The interviews for women and male partners were conducted separately to avoid influence from either party in responding. A Separate focus group discussion was conducted for the women who had delivered and admitted at the post-natal ward and male partners who met the inclusion criteria. Each focus group discussion had 6 members each. The FGDs were done after the administration of the questionnaires. The participants of the FGDs were different from those who were interviewed. The FGDs were carried out at the lactation centre at maternity for the women and at Coast Level Five Hospital boardroom for male partners respectively. The FGDs were moderated by this researcher and a research assistant who assisted with tape recording and note taking. A focus discussion guide was used when conducting the discussions. The discussions concentrated on the role played by the male partner in choice and access of Coast Level Five Hospital as the choice of delivery site, knowledge and perception. Each FGD lasted one and half hours.

\section{Data analysis}

Data was analysed using SPSS version 20.0 manufactured by IBM, in Armonk, New York USA. Knowledge was measured based on respondents' scores from a set of questions in which the correct response was awarded 1 score and none for a wrong response.

Perception level was determined based on the respondents' perception of male partner involvement in the four RH-related activities using the likert scale. The likert scale had scores ranging from $0=$ strongly disagree to $5=$ strongly agree. The cumulative scores of women and male partners on knowledge and perception obtained separately were used to calculate the mean scores; which were in turn used as a cut-offs. Scores that were equal to or above the respective mean were regarded as good knowledge and positive perception respectively, and vice versa. 
Table 1: Couples Knowledge of Male Partner Involvement in Choice of Delivery Site and its Benefits

\begin{tabular}{lllll}
\hline $\begin{array}{l}\text { Meaning, awareness and importance of male partner involvement } \\
(\mathrm{N}=\mathbf{2 0 7})\end{array}$ & $\begin{array}{l}\text { Women } \\
\text { No(\%) }\end{array}$ & $\begin{array}{l}\text { Male partners } \\
\text { No (\%) }\end{array}$ \\
\hline
\end{tabular}

1. The meaning of male partner involvement in choice of delivery site

a) The male partner alone deciding the site of delivery

b) The couple discussing, jointly choosing the site and the male partner providing logistical support to access the site

c) The male partner and his brothers and parents deciding the site

d) The woman deciding alone and informing the male partner

e) No idea

2. Aware of the need to have male partners involved in choice of delivery site

a) No

b) Yes

$73(35.3) \quad 65(31.4)$

$107(51.7) \quad 118(57.0)$

$5(2.4) \quad 4(1.9)$

$22(10.6) \quad 6(2.9)$

$0(0.0) \quad 14(6.8)$

3. It is necessary /important to involve male partners in Choice of the delivery site

a) No

b) Yes

4. The importance/benefit of male partner involvement in choosing the delivery site

a) Not stated /involvement unnecessary
b) For logistical support before and after delivery e.g. money \& transport

c) In case of problems/complications he can assist early enough

$8(3.9) \quad 14(6.8)$

$199(96.1) \quad 193(93.3)$

d) For safe and quality services during delivery as he will follow the labour progress and assist as necessary

e) The male partner is household head this is done as a sign of respect

$5(2.4) \quad 8(2.4)$

$202(97.6) \quad 199(96.1)$

f) Pregnancy and childbirth is a responsibility for both and for good outcome, the male should be involved

g) The male partner is more knowledgeable and is able to help

$14(6.7) \quad 25(12.1)$

$36(17.4) \quad 30(14.5)$

$57(27.5) \quad 31(15.0)$

$13(6.3) \quad 42(20.3)$

$45(21.7) \quad 44(21.3)$

$39(18.8) \quad 30(14.3)$

$3(1.4) \quad 3(1.4)$

h) It makes it easy to follow advice given by health workers

$0(0.0) \quad 2(1.0)$

Frequencies were used to describe the findings. Chisquare was used to test the association between knowledge and perception and level of male involvement. Logistic regression was used for estimating association of potential predictors of male partner involvement. The findings were presented using tables, bar graphs, pie charts and text.

The qualitative data that was tape-recorded was transcribed and analysed for content with similar categories grouped into sub-themes and themes. Results were presented as direct quotes from participants or as narrations. These results were finally triangulated with the quantitative data. All pvalues $\leq 0.05$ were considered statistically significant.

\section{Ethical considerations}

Ethical clearance was obtained from Kenyatta University ethics review committee (KU-ERC) and a research permit was obtained from National
Commission for Science, Technology and Innovation (NACOSTI). The hospital management gave permission to conduct the study at the hospital. Informed consent was obtained from all respondents who participated in the study. Confidentiality was maintained throughout the study by ensuring anonymity of the study respondents' information.

\section{Results}

\section{Socio-demographic characteristics of the study participants}

Most women $(73.9 \%, \mathrm{n}=153)$ were aged $20-30$ years while $16.9 \%(\mathrm{n}=35)$ were aged $31-40$ years and $9.2 \%(\mathrm{n}=19)$ were aged below 20 years. For male partners, most of them $(55.6 \%, \mathrm{n}=115)$ were within 20-30 years, $35.3 \%(n=73)$ were between $31-40$ years with $9.1 \%(\mathrm{n}=19)$ aged over 40 years. Of these women, $50.7 \%(\mathrm{n}=105)$ had primary education and below while $39.1 \%(n=81)$ of male partners had secondary education level. Most women (65.7\%, 
Onchong'a et al.

$\mathrm{n}=136$ ) earned below kshs. 5000 while most male partners $(29.0 \% \mathrm{n}=60)$ earned between kshs. 5000kshs. 10000 .

\section{Level of male partner involvement in choice of delivery site}

Regarding male partners' involvement in choice of delivery site, $40.6 \%(n=84)$ of women and male partners $40.6 \% \quad(n=84)$ reported that the male partners were involved in discussing and jointly choosing the delivery site and the male partner supported their spouses to access the chosen delivery site. In the context of this study, $40.6 \%$ of the male partners were therefore involved in choice of delivery site.

\section{Influence of knowledge and perception on male partner involvement in choice of delivery site}

The responses of women and their male partners on the meaning of male partner involvement, awareness of the need for male involvement, whether it is necessary to involve male partners and the importance of involvement in choice of delivery site were used to assess their knowledge of male partner involvement in choice of delivery choice. Table 1 shows that although most women and male partners were aware of the need for male involvement, agreed that it was necessary, there were variations on their understanding of what male partner involvement entails and the importance of male partner involvement in choice of delivery site.

Each correct response to each question was awarded a score and zero for incorrect responses. The women and male partners' cumulative scores were used to obtain their mean scores separately. Their mean scores were 3.15 and 3.12 for women and male partners respectively (max.4). Those women and male partners whose cumulative score was below their respective mean were regarded as lacking adequate information on male partner involvement in choice of delivery choice- hence had poor knowledge of male partner involvement and vice versa. Based on the above criteria, this study established that $60.1 \% \quad(n=126)$ of the women and $62.3 \%(n=129)$ of the male partners interviewed had poor knowledge of male partner involvement in choice of delivery site. In both FGD's, poor knowledge of male partner involvement in choice of delivery site was established. For instance, one woman participant understood it to mean "The male partner should
Knowledge, Perception and Male Involvement decide where to deliver". Another participant in the same group said it implied "The wife decides where to deliver and informs the husband".

\section{The effect of couple knowledge on male partner involvement}

The effect of the level of women and male partners' knowledge on male partner involvement in choice of delivery site is presented in Table 2. The study established that women knowledge significantly influenced male partner involvement in choice of delivery site with $59.3 \%(n=48)$ of male partners involved in choice of delivery site when the women had good knowledge $(\chi 2-19.256$, df- $1, \mathrm{P}<0.001)$. However, this was not the case for male partners' knowledge.

\section{Couple perception of male partner involvement in $\mathrm{RH}$ activities}

In order to ascertain the respondents' level of perception on male partner involvement in choice of delivery site, the respondents were asked to give their perception of male partners involved in selected reproductive health (RH) activities: accompanying the spouses to ANC, discussing maternal health issues (FP, ANC etc.), participating in choice of delivery site and escorting the spouse to the chosen delivery site as shown in Table 3 . Scores on the four activities were used to determine their perception level following the steps used in assessing knowledge.

Table 2: The Level of Women and Male Partners' Knowledge and Male Partner Involvement in Choice of Delivery Site

\begin{tabular}{|c|c|c|c|c|c|}
\hline \multirow[b]{2}{*}{$\begin{array}{l}\text { Level of } \\
\text { knowledge }\end{array}$} & \multicolumn{2}{|c|}{ Male involvement } & \multirow[b]{2}{*}{$\mathbf{X}$} & \multirow[b]{2}{*}{ df } & \multirow[b]{2}{*}{$\mathbf{p}$} \\
\hline & $\begin{array}{l}\text { Not } \\
\text { involved } \\
\text { n (\%) }\end{array}$ & $\begin{array}{l}\text { Involved } \\
\text { n (\%) }\end{array}$ & & & \\
\hline \multicolumn{6}{|l|}{$\begin{array}{l}\text { Women } \\
\text { knowledge }\end{array}$} \\
\hline Poor & $90(71.4)$ & $36(28.6)$ & 19.25 & 1 & $<0.0$ \\
\hline knowledge & & & 6 & & 01 \\
\hline $\begin{array}{l}\text { Good } \\
\text { knowledge }\end{array}$ & $33(40.7)$ & $48(59.3$ & & & \\
\hline $\begin{array}{l}\text { Male } \\
\text { knowledge }\end{array}$ & & & & & \\
\hline $\begin{array}{l}\text { Poor } \\
\text { knowledge }\end{array}$ & $81(62.8)$ & $48(37.2)$ & 1.613 & 1 & $\begin{array}{l}0.20 \\
4\end{array}$ \\
\hline $\begin{array}{l}\text { Good } \\
\text { knowledge }\end{array}$ & $42(53.8)$ & $36(46.2)$ & & & \\
\hline
\end{tabular}

This study revealed that $76.0 \%(\mathrm{n}=158)$ of the women and $67.0 \%(n=138)$ of male partners interviewed had negative perception of male partners' involvement in selected RH activities. In 
Table 3: Perception of Couples of Male Involvement in Selected RH Activities (N=207)

Birth Interval and its Predictor

\begin{tabular}{|c|c|c|c|c|c|c|c|c|c|c|}
\hline \multirow{3}{*}{$\begin{array}{l}\text { The male partner } \\
\text { should: } \\
\text { 1. Accompany the } \\
\text { spouse to ANC. }\end{array}$} & \multicolumn{2}{|c|}{$\begin{array}{l}\text { Strongly } \\
\text { Disagree } \\
\text { n }(\%) \\
\end{array}$} & \multicolumn{2}{|c|}{$\begin{array}{l}\text { Disagree } \\
\text { n (\%) }\end{array}$} & \multicolumn{2}{|c|}{$\begin{array}{l}\text { Undecided } \\
\text { n (\%) }\end{array}$} & \multicolumn{2}{|l|}{$\begin{array}{l}\text { Agree } \\
\text { n (\%) }\end{array}$} & \multicolumn{2}{|c|}{$\begin{array}{l}\text { Strongly } \\
\text { Agree } \\
\text { n (\%) }\end{array}$} \\
\hline & W & $\mathbf{M}$ & W & M & W & $\mathbf{M}$ & $\mathbf{W}$ & M & W & $\mathbf{M}$ \\
\hline & $\begin{array}{l}0 \\
(0.0)\end{array}$ & $4(1.9)$ & $\begin{array}{l}8 \\
(3.9)\end{array}$ & $\begin{array}{l}10 \\
(4.8)\end{array}$ & $\begin{array}{l}8 \\
(3.9)\end{array}$ & $\begin{array}{l}19 \\
(9.2)\end{array}$ & $\begin{array}{l}157 \\
(75.8)\end{array}$ & $\begin{array}{l}116 \\
(56.0)\end{array}$ & $\begin{array}{l}34 \\
(16.4)\end{array}$ & $\begin{array}{l}58 \\
(28.0)\end{array}$ \\
\hline $\begin{array}{l}\text { 2. Discuss maternal } \\
\text { health issues (FP, } \\
\text { ANC etc). }\end{array}$ & $\begin{array}{l}0 \\
(0.0)\end{array}$ & $\begin{array}{l}6 \\
(2.9)\end{array}$ & 3 & $\begin{array}{l}3 \\
(1.4)\end{array}$ & $\begin{array}{l}6 \\
(2.9)\end{array}$ & $\begin{array}{l}6 \\
(2.9)\end{array}$ & $\begin{array}{l}160 \\
(77.3)\end{array}$ & $\begin{array}{l}134 \\
(64.7)\end{array}$ & $\begin{array}{l}38 \\
(18.4)\end{array}$ & $\begin{array}{l}58 \\
(28.0)\end{array}$ \\
\hline $\begin{array}{l}\text { 3. Participate in } \\
\text { choice of delivery } \\
\text { site. }\end{array}$ & $\begin{array}{l}0 \\
(0.0)\end{array}$ & $\begin{array}{l}6 \\
(2.9)\end{array}$ & $\begin{array}{l}5 \\
(2.4)\end{array}$ & $\begin{array}{l}3 \\
(1.4)\end{array}$ & $\begin{array}{l}3 \\
(1.4)\end{array}$ & $\begin{array}{l}7 \\
(3.4)\end{array}$ & $\begin{array}{l}176 \\
(85.0)\end{array}$ & $\begin{array}{l}143 \\
(69.1)\end{array}$ & $\begin{array}{l}23 \\
(11.1)\end{array}$ & $\begin{array}{l}48 \\
(23.2)\end{array}$ \\
\hline $\begin{array}{l}\text { 4. Escort the spouse } \\
\text { to the delivery site. }\end{array}$ & $\begin{array}{l}0 \\
(0.0)\end{array}$ & $\begin{array}{l}7 \\
(3.4)\end{array}$ & $\begin{array}{l}7 \\
(3.4)\end{array}$ & $\begin{array}{l}5 \\
(2.4)\end{array}$ & $\begin{array}{l}2 \\
(1.0)\end{array}$ & $\begin{array}{l}8 \\
(3.9)\end{array}$ & $\begin{array}{l}166 \\
(80.2)\end{array}$ & $\begin{array}{l}126 \\
(60.9)\end{array}$ & $\begin{array}{l}32 \\
(15.5)\end{array}$ & $\begin{array}{l}61 \\
(29.5)\end{array}$ \\
\hline
\end{tabular}

Table 4: Influence of couple perception on male partner involvement

\begin{tabular}{|c|c|c|c|c|c|}
\hline \multirow[b]{2}{*}{ Level of perception } & \multicolumn{5}{|c|}{ Male involvement $(\mathrm{N}=207)$} \\
\hline & $\begin{array}{l}\text { Not } \\
\text { involved } \\
\text { n (\%) }\end{array}$ & $\begin{array}{l}\text { Involved } \\
\text { n (\%) }\end{array}$ & $\chi$ & df & $\mathbf{p}$ \\
\hline \multicolumn{6}{|l|}{ Women perception } \\
\hline Negative perception & $104(65.8)$ & $54(34.2)$ & \multirow{3}{*}{11.347} & \multirow{3}{*}{1} & \multirow{3}{*}{0.001} \\
\hline Positive perception & $19(38.8)$ & $30(61.2)$ & & & \\
\hline Male perception & & & & & \\
\hline Negative perception & $93(67.4)$ & $48(32.6)$ & \multirow{2}{*}{10.909} & \multirow{2}{*}{1} & \multirow{2}{*}{0.001} \\
\hline Positive perception & $30(43.5)$ & $39(56.5)$ & & & \\
\hline
\end{tabular}

Table 5: Logistic regression of predictors of male partner involvement

\begin{tabular}{lllllllll}
\hline & B & S.E & Wald & df & Sig. & Exp (B) & $\begin{array}{l}\text { 95\% CI } \\
\text { Lower }\end{array}$ & Upper \\
\hline Women knowledge & 1.346 & .313 & 18.538 & 1 & $\mathbf{. 0 0 0}$ & 3.843 & 2.082 & 7.093 \\
Male partner perception & -.083 & .338 & .061 & 1 & .805 & .920 & .474 & 1.784 \\
Women perception & -.276 & .362 & .582 & 1 & .445 & .759 & .374 & 1.542 \\
Constant & -.476 & .406 & 1.375 & 1 & .241 & .621 & & \\
\hline
\end{tabular}

contrast, most participants in both FGD's had $(\chi 2-11.347$, df- $1 \mathrm{p}=0.001$ and $\chi 2-10.909$, df-1, positive perception of male involvement in these RH $\mathrm{p}=0.001)$ respectively. Where women and male activities. However, some women reported negative partners had positive perception of male partners' perception and branding of those men who were involvement in selected $\mathrm{RH}$ activities, $61.2 \%$ and involved in RH activities with demeaning phrases. $56.5 \%$ of the male partners respectively were For example one participant from Kisauni sub- involved in choice of delivery site. county said

"The husband's family members see you as controlling the husband and so he listens to you more".

\section{The role of the level of couples' perception on} male partner involvement

\section{Predictors of male partner involvement in choice of delivery site}

To establish the determinants of male partner involvement in choice of delivery site, logistic regression was performed on variables that were significant on chi-square i.e. women knowledge and women and male partners' perception. The study results showed that among these variables, only women knowledge was a predictor of male partner

As shown in Table 4, the level of women and male partners' perception played a significant role on male partner involvement in choice of delivery site 


\section{Onchong'a et al.}

involvement (OR- 3.843, 95\% CI- 2.082- 7.092, $\mathrm{p}<0.001)$. This implies that improving women knowledge from poor to good, the odds ratio for male partner involvement in choice of delivery site will increase by 3.8 times.

\section{Discussion}

Waiting for the male partner to make a decision on delivery site leads to unnecessary delay in access or lack of utilization of skilled birth attendance worsening the already high maternal mortality. However, with early male involvement enables men to support their spouses to utilize emergency obstetric services early, adequately prepare for birth and ready themselves for complications. This can lead to a reduction in all the three phases of delay (i.e. delay in making decision to seek care, delay in accessing the care and delay in receiving the care ${ }^{19}$. In addition, it has also been argued that reducing maternal deaths by $75 \%$ throughout the world by 2015 will take the involvement of men in countries where it matters most ${ }^{1}$. This study revealed that although the male partners are key decision makers and financial providers, most decisions on choice of delivery site and accessing it are made without their participation. This suggests that pregnant women are left on their own to decide and access the delivery site though in many cases they have little control over finances hence likely to experience delays or fail to access skilled birth attendance. This could be attributed to lack of programs that reach out for men hence many men may not be aware why and how they need to be involved, viewing delivery issues as women's affair, a feeling of embarrassment by male partners when participating and culturally defined gender roles in many countries may hinder male participation ${ }^{6}$. In addition, it may also be due to low education level especially among women making it difficult to comprehend health messages, follow them or even share them with their male partners. This is consistent with results of studies done in Uganda $^{10}$, in Kenya ${ }^{11}$ and in Senegal ${ }^{9}$. However, it differs significantly with studies conducted in Kenya $^{2}$ and in Ethiopia ${ }^{8}$. The differences could be attributed to narrow definition of male partner involvement in these other studies whereby they viewed male involvement as just making a joint decision on site of delivery unlike in this study where male partner involvement includes making a joint decision on the site of delivery and facilitating the woman to access the delivery site. Therefore
Knowledge, Perception and Male Involvement there is a need to promote male partner involvement to reduce these delays and promote skilled birth attendance.

Educating women and their spouses about the complications of pregnancy and child birth leads to increased uptake of maternal and child health services ${ }^{13}$. This study established that most women $(60.1 \%)$ and most male partners $(62.3 \%)$ had poor knowledge of male partner involvement in choice of delivery site and its benefits. This is possibly as a result of low standards of education and poor or lack of programs with deliberate efforts to create awareness in the community on male partner involvement in child birth-related activities. In addition, health education on male involvement may not be given the priority it deserves during routine ANC health talks. These findings are in agreement with those of a study in Kenya ${ }^{14}$ and in Nepal ${ }^{13}$. Furthermore, this study revealed that poor women knowledge of male involvement and its benefits was a hindrance to male partner involvement. This is true because women most often attend ANC unaccompanied by their spouses and if they know little about male partner involvement, they will have nothing to share with their partners after the ANC attendance or simply put they can't share what they know little or completely don't know. This result supports findings of a study in $\mathrm{Nepal}^{13}$ and findings of a study done in Busia, Kenya ${ }^{14}$. Therefore there is need to empower women with adequate and accurate knowledge on male partner involvement and its benefits to improve male partner involvement in not only choice of delivery site but also in other maternal and neonatal health issues. Several studies have reported negative perceptions towards men attending ANC services. Frequently, men perceive that ANC services are designed and reserved for women, thus are embarrassed to find themselves in such "female" places ${ }^{15}$. Consistent with poor knowledge, most women and their male partners in this study had negative perception of male partner involvement in reproductive health activities. Negative perception could be due to the view that delivery is a natural phenomenon, fear of ridicule and lack of knowledge especially among $\operatorname{men}^{14}$, and may be because of poor knowledge of male partner involvement and its benefits among the respondents as significant proportions of both women and male partners' had poor knowledge $(60.1 \%$ and $62.3 \%$, respectively).This finding is consistent with findings of a study in Kenya ${ }^{14}$ where poor perception was also established. 
Onchong'a et al.

Negative perception of male partners involved in $\mathrm{RH}$ activities posed a challenge to male partner involvement. This is in tandem with results of a study in Nepal where the researcher argued that ridicule and teasing a male when trying to get involved might discourage him ${ }^{13}$, with results of a study in Busia, Kenya where the researchers argued that many men regarded delivery as a natural phenomenon and saw no need to be involved ${ }^{14}$. Other researchers argued that fear of being viewed as a jealous husband may make a man not to be involved in $\mathrm{ANC}^{17}$. As shown in a study in Asembo Kenya some men view male involvement in delivery issues as less important compared to striving to achieve economic wellbeing of the family ${ }^{12}$. Women perceiving child birth as a women affair that does not require male partner involvement may contribute to low male partner involvement as established by ${ }^{18}$. (This can be viewed as some of the negative perceptions held by male partners). Fear of being ridiculed by the community members, being branded some demeaning phrases may lead to negative perception ${ }^{18}$. These negative attributes were particularly expressed during FGD. A member of the FGD said "the husband's family members see you as controlling the husband and so he listens to you more". Such negative attributes will make many male partners to avoid being involved. In Nepal family members ridiculed and teased a male partner when trying to be involved in maternal health and were discouraged by this ${ }^{13}$. Furthermore, several Nepali phrases or idioms had been coined for husbands who were viewed as 'too' supportive or involved with their wives ${ }^{13}$. Knowledge of male partner involvement in choice of delivery site, its benefits and perception of male involvement in $\mathrm{RH}$ activities have some influence in male partner involvement in choice of delivery site. There is need for practical and locally acceptable strategies to improve the knowledge and address the negative perception to improve male partner involvement.

This study has several limitations. Firstly, it was conducted in a health facility and therefore the results may be different from those of a community based study. Secondly, the respondents were interviewed after the women had delivered. The outcome of the pregnancy to some extent might have influenced the participants' responses and hence the findings. Nevertheless, this study provides some useful evidence that can be used as a basis for promotion of male partner involvement in choice of delivery site.
Knowledge, Perception and Male Involvement

\section{Conclusion}

This study established low male partner involvement in choice of delivery site. In addition, most participants in this study had poor knowledge of male partner involvement in choice of delivery site and negative perception of male partners involved in reproductive health activities. This implies knowledge gaps that need to be addressed. Furthermore, poor women knowledge and negative perception of both the women and male partners hindered involvement of male partners in choice of delivery site. Therefore these researchers recommend that the management of Coast Level Five Hospital and Mombasa County government should come up with strategies and Programs that will promote male involvement in reproductive health by creating awareness on the benefits of male partner involvement through various modalities such as mass media, health talks at ANC, providing information, education and communication materials and community outreaches.

\section{Acknowledgement}

The researchers acknowledge the moral support received from Nemwel Onchong'a and Peace Mangale.

\section{Conflict of Interest}

The authors' declare no conflict of interest in relation to this study.

\section{Contributions of Authors}

James M. Onchong'a conceived the study idea, prepared the data collection tools and collected data. Tom Were and Justus O.S. Osero participated in data analysis and reviewed the manuscript.

\section{References}

1. World health organization: Reproductive Health Report; 2010; Geneva, WHO

2. Kenya National Bureau of Statistics: Kenya Demographic and Health Survey 2008 report Calverton, 2009; Maryland, USA

3. Berhane Y. Male involvement in reproductive health. Ethiop J Health Dev 2006; 20 (3):135-136.

4. Iliyasu Z, Abubakar IS, Galadanci HS, \& Aliyu MH: Birth preparedness, complication readiness and fathers' participation in maternity care in Northern Nigeria community. African Journal of Reproductive Health, 2010; 14:21-32.

5. Babalola, S., \& Adesegun, F., Determinants of 


\section{Onchong'a et al.}

use of maternal health services in Nigeria - looking beyond individual and household factors BMC Pregnancy and Childbirth, (2009): 9 (43), 2393-2943

6. Naomi W. Challenges and Opportunities for Male Involvement in Reproductive Health in Cambodia. 2005; Policy Project/Cambodia.

7. Mpembeni RNM, Killewo JZ, Leshabari MT, Massawe SN, Jahn A, Mushi D, et al. Use pattern of maternal health services and determinants of skilled care during delivery in Southern Tanzania: Implications for achievement of MDG-5 targets. BMC Pregnancy Childbirth 2007; 7:29. doi: 1086/1471-2393-7-29.

8. Wassie L, Bekele A, Ismael A, Tariku N, Heran A, Getnet M, Mitike M, Adamu A, Seifu H. Magnitude and factors that affect males' involvement in deciding partners' place of delivery in Tiyo District of Oromia Region, Ethiopia. Ethiop. J. Health Dev. 2014; (Special Issue 1).

9. Dia A. Maternal mortality in Senegal: contributing factors in the health system and the community, 2005.

10. Kabakyenga JK, Ostergren PO, Turyakira E, Pettersson KO. : Influence of birth preparedness, decisionmaking on location of birth and assistance by skilled birth attendants among women in south western Uganda, PLOS ONE, 2012; 7(4).

11. Wanjira C, Mwangi M, Mathenge E, Mbugua G.

Ng'ang'a Z. Delivery practices and Associated Factors among Mothers Seeking Child Welfare Services in selected Health Facilities in Nyandarua South District, Kenya. BMC public health; 2011; 11:360.

12. Kwambai T, Stephanie MD, Charles AA, Bobbie P, Florence A, Linda M, Kayla FL, Feiko OK. Perspectives of men on antenatal and delivery care
Knowledge, Perception and Male Involvement service utilisation in rural western Kenya: a qualitative study. BMC Pregnancy and Childbirth, 2013; 13:134.

13. Mullany BC. Barriers to and attitudes towards promoting husbands' involvement in maternal health in Katmandu, Nepal. Soc Sci Med, 2006; 62:27982809

14. Nanjala M, wamalwa D. Determinants of male partner involvement in promoting deliveries by skilled attendants in Busia, Kenya. Global Journal of health sciences, 2012, vol. 4 no. 2

15. Byamugisha R, Tumwine JK, Semiyaga N, \& Tylleskär T. Determinants of male involvement in the prevention of mother-to-child transmission of HIV programme in Eastern Uganda: a cross-sectional survey. Reprod Health, 2010; 7:12.

16. Onyango MA, Owoko S, Oguttu M. Factors that Influence Male Involvement in Sexual and Reproductive Health in Western Kenya: A Qualitative Study. African Journal of Reproductive Health, 2010; 14 (4): 42.

17. Nkuoh GN, Meyer DJ, Tih PM, Nkfusai J. Barriers to men's participation in antenatal and prevention of mother-to-child HIV transmission care in Cameroon, Africa. J Midwifery Women's Health, 2010; 55(4): 363-9.

18. Kululanga L, Sundby J, Malata A, Chirwa E. Male involvement in maternity health care in Malawi. African Journal of Reproductive Health, 2012; 16 (1): 145.

19. Odimegwu C, Adewuyi A, Odebiyi T, Aina B, Adesina OO, Eniola F. Men's role in Emergency Obstetric Care in Osun state of Nigeria, African J. of Reprod. Health, 2005; 9(3):59-71. 